\title{
SAÚDE E QUALIDADE DE VIDA DE POLICIAIS MILITARES
}

\section{Health and quality of life of military police officers}

\section{Salud y calidad de vida del personal militar}

\author{
Thiago Roberto Arroyo iD \\ Faculdade de Medicina de São José do Rio Preto - FAMERP - São José do Rio Preto (SP) - Brasil \\ Centro Universitário do Norte Paulista - UNORP - São José do Rio Preto (SP) -Brasil
}

\author{
Marcio Andrade Borges (iD \\ Damásio Educacional - Vitória (ES) - Brasil
}

\section{Luciano Garcia Lourenção iD}

Universidade Federal do Rio Grande - FURG - Rio Grande (RS) - Brasil

\section{RESUMO}

Objetivo: Avaliar a qualidade de vida de policiais militares e comparar com as variáveis sexo, tempo de atuação profissional, turno e carga horária de trabalho. Métodos: Estudo transversal com 506 policiais, realizado no Comando de Policiamento

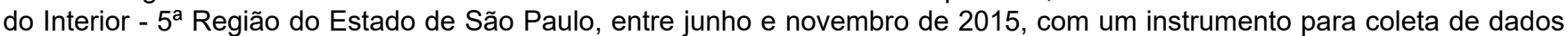
sociodemográficos e o WHOQOL-Bref, da Organização Mundial de Saúde. Calculou-se a média dos escores do WHOQOL-Bref conforme modelo estatístico disponibilizado pelo Grupo WHOQOL. Resultados: Sexo masculino (449; 88,7\%), idade mediana de 36 anos, casados $(338 ; 66,8 \%)$, soldados $(195 ; 38,5 \%)$ e cabos $(161 ; 31,8 \%)$, mais de 10 anos de atuação policial $(283 ; 55,9 \%)$, qualidade de vida boa ou muito boa $(414 ; 81,8 \%)$, satisfeitos ou muito satisfeitos com a saúde (383; $75,7 \%)$. Maior escore de qualidade de vida para o domínio Relações Sociais $(75,1)$ e menor para Meio Ambiente $(62,2)$. Comprometimento das facetas Recursos financeiros $(49,8)$ e Recreação e lazer $(48,8)$. Conclusão: Os policiais militares avaliados consideram a qualidade de vida boa ou muito boa e encontram-se satisfeitos com a saúde. Há, no entanto, comprometimento da qualidade de vida dos profissionais nos fatores relacionados ao domínio Meio Ambiente.

Descritores: Qualidade de Vida; Promoção da Saúde; Militares; Saúde do Trabalhador.

\begin{abstract}
Objective: To evaluate the quality of life of military police officers and compare it to with sex, length of time working in the profession, shift and workload. Methods: Cross-sectional study with 506 police officers, conducted at the Inland Police Command - 5th Region of the State of São Paulo, between June and November 2015, with an instrument for collecting sociodemographic data and the WHOQOL-Bref by the World Health Organization. The mean of WHOQOL-bref scores was calculated according to the statistical model provided by the WHOQOL Group. Results: Male gender (449;88.7\%), median age 36 years, married (338;66.8\%), sergeants (195;38.8\%) and aspirants (161;31.8\%), more than 10 years of police activity (283;55.9\%), good or very good quality of life (414;81.8\%), satisfied or very satisfied with health (383;75.7\%). Highest quality of life score for Social Relations (75.1) and lowest for Environment (62.2). The domains Financial resources (49.8) and Recreation and leisure (48.8) were compromised. Conclusion: The military police officers assessed consider regard their quality of life as good or very good and are satisfied with their health. There is, however, a compromise in the quality of life of these professionals, in aspects related to the domain Environment.
\end{abstract}

Descriptors: Quality of Life; Health Promotion; Military Personnel; Occupational Health.

\section{RESUMEN}

Objetivo: Evaluar la calidad de vida del personal militar y compararla con las variables sexo, tiempo de actuación profesional, turno y carga horaria de trabajo. Métodos: Estudio transversal con 506 policías realizado en el Comando de Vigilancia Policial del Interior - 5a Región del Estado de São Paulo entre junio y noviembre de 2015 con un instrumento para la recogida de datos sociodemográficos y el WHOQOL-Bref de la Organización Mundial de la Salud. Se calculó la media de puntuaciones del WHOQOL-Bref según el modelo estadístico disponible en el Grupo WHOQOL. Resultados: Sexo masculino (449; 88,7\%), edad mediana de 36 años, casados (338;66,8\%), soldados (195; 38,5\%) y cabos (161; 31,8\%), más de 10 años de actuación

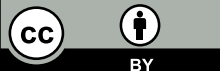


en la policía (283; 55,9\%), calidad de vida buena o muy buena (414; 81,8\%), satisfechos o muy satisfechos con la salud (383; $75,7 \%)$. Mayor puntuación de la calidad de vida para el dominio Relaciones Sociales $(75,1)$ y menor para el Medio Ambiente $(62,2)$. Comprometimiento de las facetas Recursos financieros $(49,8)$ y Recreación y ocio $(48,8)$. Conclusión: Los policías militares evaluados consideran la calidad de vida buena o muy buena y están satisfechos con su salud. Hay, sin embargo, el comprometimiento de la calidad de vida de los profesionales para los factores relacionados con el dominio Medio Ambiente.

Descriptores: Calidad de Vida; Promoción de la Salud; Personal Militar; Salud Laboral.

\section{INTRODUÇÃO}

As altas exigências do ambiente militar, associadas ao aumento da violência e à falta de preparo ou de condições profissionais e de auxílio pessoal, necessários ao bom desempenho profissional, fazem do trabalho dos policiais um dos mais desgastantes. $O$ estresse decorrente da atividade laboral representa potencial perigo para a saúde dos policiais, uma vez que as condições de saúde desses profissionais envolvem prazer e sofrimento, que levam à realização e ao desgaste; a riscos vividos e percebidos, que estruturam a profissão; e a agravos físicos, decorrentes das condições de vida e trabalho, associados às condições biológicas ${ }^{(1-3)}$.

O cansaço físico e a falta de equilíbrio emocional podem levar os profissionais a adotarem atitudes irracionais durante crises e situações caóticas, que podem acarretar a falta de eficácia no desempenho do exercício profissional e expor os policiais e a população ao risco de dano e morte(4). Portanto, é necessário avançar na compreensão dos aspectos ambientais, psicológicos, sociais e físicos que envolvem a qualidade de vida dos policiais militares e implementar ações de promoção da saúde que melhorem as condições de vida, de saúde e de trabalho desses profissionais $^{(5)}$.

Há evidências de que os profissionais do sexo masculino apresentam melhor qualidade de vida dos que as policiais, que tendem a relacionar o cotidiano de trabalho ao estresse, percebem maior influência dele na sua saúde e identificam consequências negativas no relacionamento familiar ${ }^{(3,6)}$. É comum, ainda, que esses profissionais apresentem desgastes físicos e emocionais ${ }^{(5)}$, elevados níveis de estresse ${ }^{(3)}$, grande número de acidentes de trabalho, doenças crônicas, sobrepeso e tenham maior risco de desenvolvimento de doenças cardiovasculares ${ }^{(7)}$.

O principal estressor para os policiais é a excessiva carga de trabalho, que, associada ao regime de escalas e à inflexibilidade de horários, desencadeia problemas de saúde digestivos, musculares e do sistema nervoso, os quais causam sintomas, tais como: dores no pescoço e nas costas ou na coluna, cefaleia, dificuldade de concentração, problemas de visão e insônia( ${ }^{(3,8)}$.

Para melhorar as condições de vida e reduzir as vulnerabilidades e os riscos à saúde relacionados ao ambiente e ao processo de trabalho dos policiais, como determina a Política Nacional de Promoção da Saúde, faz-se necessário identificar os fatores associados ao comprometimento da qualidade de vida desses profissionais, os quais poderão subsidiar decisões e intervenções que promovam saúde e qualidade de vida(9).

Ante o exposto, este estudo objetivou avaliar a qualidade de vida de policiais militares e comparar com as variáveis sexo, tempo de atuação profissional, turno e carga horária de trabalho.

\section{MÉTODOS}

Trata-se de um estudo transversal com amostra de conveniência composta por policiais militares do Comando de Policiamento do Interior - $5^{\text {a }}$ Região (CPI-5) do estado de São Paulo, que abrange uma área de 96 municípios e 1,4 milhões de habitantes.

O CPI-5 é constituído pelas seguintes Unidades de Policiamento(10): $16^{\circ}$ Batalhão de Polícia Militar do Interior, sediado em Fernandópolis (Regiões de Governo de Fernandópolis, Jales e Votuporanga); $17^{\circ}$ Batalhão de Polícia Militar do Interior, sediado em São José do Rio Preto (Região de Governo de São José do Rio Preto); $52^{\circ}$ Batalhão de Polícia Militar do Interior, sediado em Mirassol (Região de Governo de Mirassol); $30^{\circ}$ Batalhão de Polícia Militar do Interior, sediado em Catanduva (Região de Governo de Catanduva).

Na Polícia Militar do Estado de São Paulo existem os seguintes níveis hierárquicos: oficiais (coronel, tenente coronel, major, capitão, $1^{\circ}$ tenente e $2^{\circ}$ tenente), praças especiais (aspirante a oficial e aluno oficial) e os praças (subtenente, $1^{\circ}$ sargento, $2^{\circ}$ sargento, $3^{\circ}$ sargento, aluno sargento, cabo e soldado) ${ }^{(11)}$. Esses profissionais trabalham em viaturas ou motos, fazendo o patrulhamento nas ruas e em escolas, bem como no atendimento de ocorrências e em funções administrativas e gerenciais (chefias). 
A população se constituiu por todos os 2.024 policiais militares pertencentes ao Comando de Policiamento do Interior que, voluntariamente, consentiram participar do estudo. Todos os policiais presentes no quadro de funcionários ativos foram incluídos no estudo. Excluíram-se os profissionais que estavam de férias ou afastados das atividades profissionais, por qualquer outro motivo, no período da coleta dos dados.

A coleta dos dados ocorreu no período de junho a novembro de 2015 e utilizaram-se dois instrumentos: um instrumento elaborado pelos autores para coletar informações sobre o perfil sociodemográfico dos policiais e a versão abreviada do Instrumento de Avaliação de Qualidade de Vida da Organização Mundial de Saúde (WHOQOL-Bref) ${ }^{(12)}$.

O WHOQOL-Bref é composto por 26 questões, das quais somente duas são gerais: uma se refere à vida e a outra, à saúde. As demais 24 perguntas são relativas a quatro domínios da qualidade de vida e suas respectivas facetas. Cada domínio tem por objetivo analisar a capacidade física, o bem-estar psicológico, as relações sociais e o meio ambiente em que o indivíduo está inserido, sendo cada um composto por questões cujas pontuações das respostas variam entre 1 e 5 . Os escores de qualidade de vida são uma escala positiva, ou seja, quanto maior o escore, melhor a qualidade de vida ${ }^{(13,14)}$.

Para a coleta dos dados, após autorização da coronel responsável pelo CPI-5, os pesquisadores contataram os comandantes dos batalhões da Polícia Militar das cidades de São José do Rio Preto, Catanduva, Mirassol e Fernandópolis, explicaram os objetivos do estudo e entregaram os instrumentos conforme o número de policiais de cada batalhão. Os comandantes foram os responsáveis por distribuir os instrumentos para os policiais, que podiam levá-los para casa para responder com privacidade. Após respondê-los, os policiais devolveram os questionários e os Termos de Consentimento Livre e Esclarecido (TCLE) assinados, em envelopes separados e fechados, para evitar identificação. Ao receber os instrumentos respondidos, os comandantes contataram os pesquisadores para a entrega de todos os envelopes.

Os cálculos dos escores do WHOQOL-Bref foram realizados conforme modelo estatístico disponibilizado pelo Grupo WHOQOL, que calcula os escores e determina os escores transformados na escala de 4 a 20 para cada faceta e cada domínio do questionário. Para favorecer a comparação com outros estudos, converteram-se os escores obtidos na escala de 4 a 20 para uma escala de 0 a 100 por meio da fórmula [(Média-4)x100/16], na qual a média corresponde aos escores de 0 a 20 calculados anteriormente para cada domínio(12-14).

Utilizaram-se os seguintes procedimentos para o cálculo da análise da qualidade de vida: a) frequências e medidas estatísticas descritivas para as questões gerais referentes à "vida" e à "saúde" dos policiais (Como você avaliaria sua qualidade de vida? Quão satisfeito (a) você está com a sua saúde?); e b) escores médios para cada domínio.

Os escores médios obtidos nos domínios do WHOQOI-Bref foram comparados com as variáveis sexo, tempo de atuação profissional, turno e carga horária de trabalho utilizando-se o teste $F$ na análise de variância (ANOVA), considerando-se um nível de significância de $5 \%(p<0,05)$.

Para verificar a distribuição dos dados, analisados com o Programa Statistical Package for Social Sciences, versão 20.0, utilizou-se teste de normalidade de Kolmogorov-Srminov.

O estudo recebeu aprovação do Comitê de Ética em Pesquisa da Faculdade de Medicina de São José do Rio Preto, sob o Parecer n. ${ }^{\circ}$ 1.183.409.

\section{RESULTADOS}

Participaram do estudo 506 policiais militares dos batalhões de Polícia Militar, equivalente a $25 \%$ da corporação (2.024 policiais), pertencentes ao Comando de Policiamento do Interior - $5^{a}$ Região, sendo: 105 policiais $(2,7 \%)$ no $16^{\circ}$ Batalhão de Polícia Militar, sediado em Fernandópolis; 79 policiais (15,6\%) no $17^{\circ}$ Batalhão, sediado em São José do Rio Preto; 50 policiais $(9,9 \%)$ no $52^{\circ}$ Batalhão, sediado em Mirassol; 133 policiais $(26,3 \%)$ no $30^{\circ}$ Batalhão, sediado em Catanduva; e 139 policiais $(27,5 \%)$ lotados na sede do Comando de Policiamento do Interior, em São José do Rio Preto. Do total, $410(81,0 \%)$ eram praças, sendo: 5 (1,0\%) subtenentes; 18 (3,6\%) sargentos; $26(5,1 \%)$ alunos sargentos; $160(31,6 \%)$ cabos e $195(38,5 \%)$ soldados. Há ainda $87(17,2 \%)$ policiais que não responderam qual era sua insígnia.

Entre os policiais que participaram do estudo, houve prevalência de sexo masculino ( $449 ; 88,7 \%)$. A idade variou de 19 a 54 anos, com mediana de 36 anos e faixa etária prevalente dos 36 aos 45 anos (202; 39,9\%). Quanto ao estado civil, observou-se que $338(66,8 \%)$ policiais eram casados e $132(26,1 \%)$, solteiros. Em relação ao tempo de atuação na PM, $283(55,9 \%)$ policiais atuavam na Polícia Militar há mais de 10 anos. Quanto à escolaridade, observou-se que 234 (46,3\%) policiais tinham ensino médio completo e $203(40,1 \%)$ possuíam ensino superior completo. Entre os profissionais estudados, havia $195(38,5 \%)$ soldados, $161(31,8 \%)$ cabos, e $46(9,1 \%)$ sargentos. 
Quanto ao turno de trabalho, observou-se que $346(68,4 \%)$ policiais trabalhavam em turno integral, sendo que 270 $(53,4 \%)$ faziam escalas de $12 \times 24$ ou $24 \times 48$ horas.

Os resultados da avaliação da qualidade de vida geral são apresentados pela distribuição da frequência de respostas, escore médio e desvio-padrão para as duas questões gerais sobre qualidade de vida (Tabela I).

Observou-se que $414(81,8 \%)$ policiais avaliaram a qualidade de vida (questão 1) como boa ou muito boa, enquanto $22(4,3 \%)$ policiais a julgaram como ruim ou muito ruim. Quando questionados sobre a satisfação com sua saúde (questão 2$), 383(75,7 \%)$ policiais referiram-se satisfeitos ou muito satisfeitos. No entanto, chama a atenção que, apesar de apenas 42 policiais $(8,3 \%)$ se referirem insatisfeitos ou muito insatisfeitos com a saúde, $81(16,0 \%)$ profissionais referiram-se nem satisfeitos, nem insatisfeitos com a sua saúde.

Tabela I - Distribuição das frequências de respostas dos policiais militares e os escores médios para as questões gerais de qualidade de vida. São Paulo, 2018.

\begin{tabular}{llc}
\hline Questão & Opções de resposta & $\mathbf{n}(\%)$ \\
\hline Como você avaliaria sua qualidade de vida? & 1- Muito ruim & $3(0,6)$ \\
& 2- Ruim & $19(3,7)$ \\
& 3- Nem ruim nem boa & $70(13,8)$ \\
& 4- Boa & $343(67,8)$ \\
& 5- Muito boa & $71(14,0)$ \\
& Escore Médio da questão & 3,9 \\
Quão satisfeito(a) você está com a sua saúde? & Desvio padrão & 0,7 \\
& 1- Muito insatisfeito & $3(0,6)$ \\
& 2- Insatisfeito & $39(7,7)$ \\
& 3- Nem satisfeito nem insatisfeito & $81(16,0)$ \\
& 4- Satisfeito & $270(53,4)$ \\
& 5- Muito satisfeito & $113(22,3)$ \\
& Escore Médio da questão & 3,9 \\
& Desvio padrão & 0,9 \\
\hline
\end{tabular}

No que diz respeito aos resultados dos domínios e facetas do WHOQOL-Bref, a Figura 1 apresenta a distribuição dos escores médios. O menor escore foi para o domínio Meio Ambiente $(62,2)$, composto pelas facetas: Segurança física e proteção; Ambiente no lar; Recursos financeiros; Cuidados de saúde e sociais: disponibilidade e qualidade; Oportunidades de adquirir novas informações e habilidades; Participação em/e oportunidades de recreação/lazer; Ambiente físico (poluição, ruído, trânsito e clima); Transporte. O maior escore obtido refere-se ao domínio Relações Sociais $(75,1)$, composta pelas facetas: Relações pessoais; Suporte (apoio) social; Atividade sexual.

Os policiais apresentaram comprometimento nas facetas Recursos financeiros $(49,8)$ e Recreação e lazer $(48,8)$, que apresentaram menores escores médios. As facetas Ambiente físico $(59,7)$ e Sono e repouso $(57,7)$ obtiveram menores escores, evidenciando que há algum comprometimento desses aspectos da qualidade de vida dos policiais estudados. A faceta Autoestima obteve maior escore entre os policiais.

Conforme mostra a Tabela II, não houve diferença significante da qualidade de vida entre policiais do sexo masculino e feminino. Contudo, observou-se menores valores médios obtidos pelas mulheres policiais nos domínios Físico, Psicológico e Relações Sociais. Observou-se, ainda, uma maior qualidade de vida no domínio Físico e menor no domínio Social entre os profissionais com maior tempo de atuação profissional; e menor qualidade de vida no domínio Físico conforme a carga horária de trabalho.

\section{DISCUSSÃO}

Os resultados sobre a qualidade de vida geral e a satisfação com a saúde dos policiais militares encontrados no presente estudo corroboram a literatura, que aponta que a maioria dos profissionais classifica de forma positiva a sua qualidade de vida e mostram uma relação também positiva de satisfação com a sua saúde ${ }^{(4,15)}$. A avaliação positiva pode estar relacionada à dificuldade de os policiais perceberem o impacto dos fatores negativos, como estresse e cansaço físico, em sua saúde e qualidade de vida ${ }^{(16)}$.

Apesar da avaliação positiva, o trabalho policial é repleto de fatores desgastantes, que causam estresse e sofrimento psíquico, evidenciando que a qualidade de vida desses profissionais está fortemente ligada a fatores sociais e psicológicos ${ }^{(4)}$. 


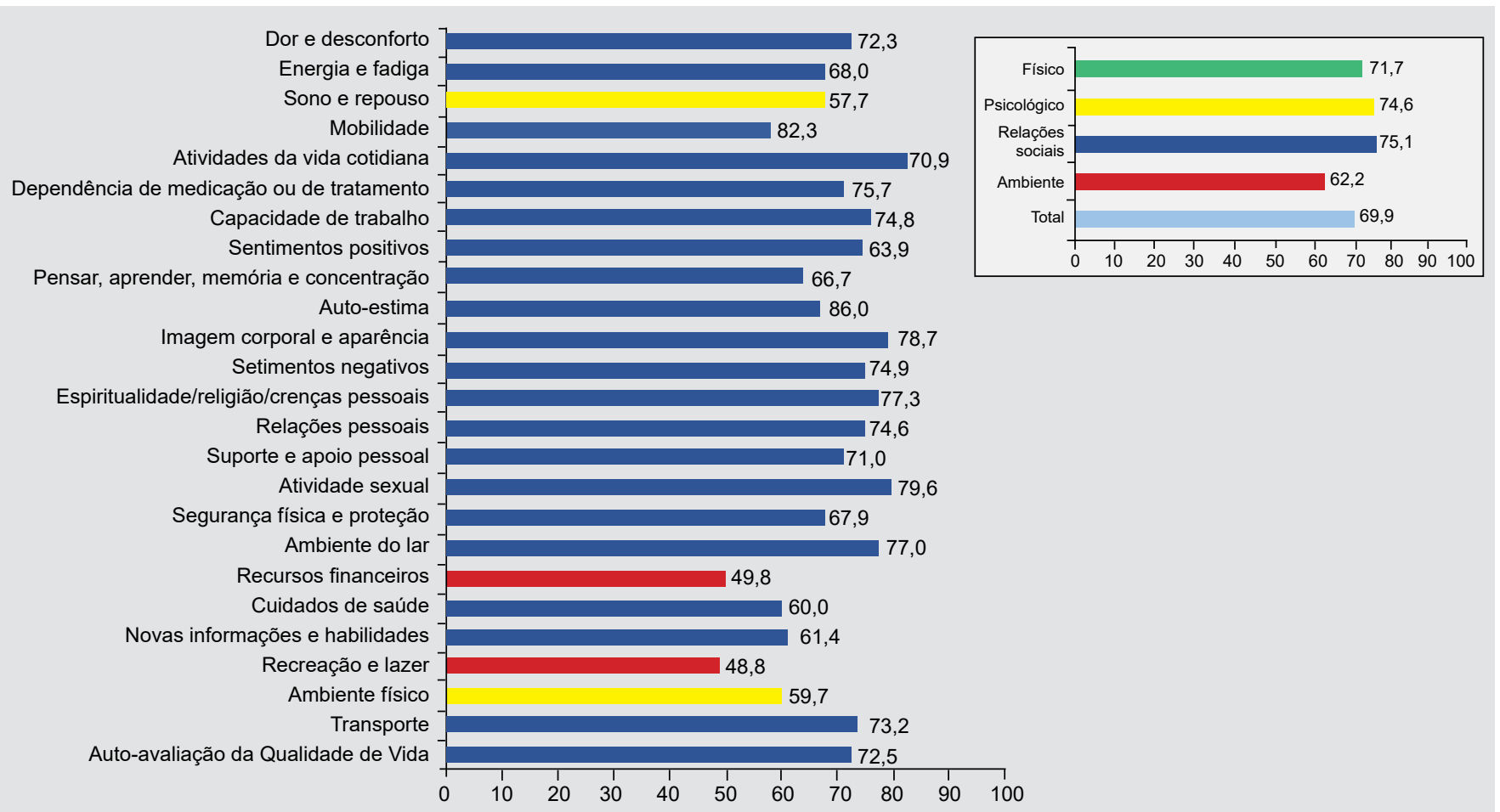

Figura 1 - Distribuição dos escores médios para os domínios e facetas do Whoqol-Bref. São Paulo, 2018.

Tabela II - Valores médios e desvio padrão para os domínios referentes à qualidade de vida dos policiais militares, segundo sexo, tempo de atuação profissional, carga horária e turno de trabalho. São Paulo, 2018.

\begin{tabular}{|c|c|c|c|c|}
\hline Qualidade de vida & $\begin{array}{c}\text { Domínio Físico } \\
\text { Média (DP) } \\
\end{array}$ & $\begin{array}{c}\text { Domínio } \\
\text { Psicológico } \\
\text { Média (DP) } \\
\end{array}$ & $\begin{array}{c}\text { Domínio Social } \\
\text { Média (DP) } \\
\end{array}$ & $\begin{array}{c}\text { Domínio } \\
\text { Ambiente } \\
\text { Média (DP) } \\
\end{array}$ \\
\hline \multicolumn{5}{|l|}{ Sexo } \\
\hline Masculino & $58,4(10,0)$ & $66,2(11,1)$ & $75,7(15,7)$ & $62,3(13,6)$ \\
\hline Feminino & $58,2(9,0)$ & $65,4(10,2)$ & $72,8(17,7)$ & $64,2(12,4)$ \\
\hline Valor-p (Anova) & 0,995 & 0,876 & 0,322 & 0,908 \\
\hline \multicolumn{5}{|l|}{ Tempo de Atuação } \\
\hline 0 a 10 anos & $57,5(9,7)$ & $67,1(10,0)$ & $77,7(16,1)$ & $63,2(14,4)$ \\
\hline 11 a 20 anos & $58,4(10,1)$ & $65,5(11,7)$ & $76,1(16,9)$ & $61,3(13,3)$ \\
\hline 21 a 30 anos & $59,7(9,7)$ & $65,5(11,3)$ & $63,2(13,5)$ & $63,4(12,1)$ \\
\hline Valor-p (Anova) & $0,034^{*}$ & 0,565 & 0,292 & 0,301 \\
\hline \multicolumn{5}{|l|}{ Carga horária de Trabalho } \\
\hline 6 horas & $73,0(12,7)$ & $73,0(2,8)$ & $87,5(17,7)$ & $70,5(24,7)$ \\
\hline 8 horas & $60,4(8,1)$ & $67,6(10,7)$ & $76,7(16,4)$ & $66,23(11,5)$ \\
\hline $12 \times 36$ horas & $57,9(11,9)$ & $65,1(12,1)$ & $72,2(16,2)$ & $63,5(13,8)$ \\
\hline $12 \times 24$ ou $12 \times 48$ & $57,0(10,0)$ & $65,5(10,8)$ & $75,2(15,6)$ & $59,8(13,9)$ \\
\hline Valor-p (Anova) & $0,002^{*}$ & 0,140 & 0,579 & $0,047^{*}$ \\
\hline \multicolumn{5}{|l|}{ Turno de Trabalho } \\
\hline Manhã & $63,0(12,2)$ & $65,4(12,8)$ & $76,5(17,4)$ & $64,1(15,8)$ \\
\hline Tarde & $57,2(9,6)$ & $70,0(2,0)$ & $81,2(8,1)$ & $54,5(3,8)$ \\
\hline Noite & $56,8(12,5)$ & $68,7(12,7)$ & $70,8(17,0)$ & $62,4(18,1)$ \\
\hline Integral & $56,2(10,7)$ & $64,4(10,0)$ & $64,1(15,8)$ & $61,2(15,1)$ \\
\hline Manhã/Noite ou Tarde/noite & $58,4(9,6)$ & $66,1(11,0)$ & $75,5(16,2)$ & $62,7(13,2)$ \\
\hline Valor $p$ (Anova) & 0,427 & 0,143 & 0,996 & 0,413 \\
\hline
\end{tabular}

${ }^{*} \mathrm{p}<0,005$; DP: desvio padrão

Alguns autores destacam que a insatisfação com o trabalho é um fator de risco para o sofrimento psíquico dos policiais militares ${ }^{(8,12,15)}$. Nesse sentido, a precariedade das condições de trabalho, caracterizada pelas excessivas cargas 
horárias de trabalho, má remuneração, falta de capacitação e de estrutura física, podem levar ao desenvolvimento de problemas de saúde que se cronificam e comprometem sua qualidade de vida ${ }^{(3,8,17)}$.

Em relação aos domínios do WHOQOL-Bref, os resultados do atual estudo mostram que não houve diferenças significantes entre os domínios, ou seja, ambos se apresentaram igualmente como potenciais influenciadores na qualidade de vida dos policiais militares.

O maior escore observado entre os policiais do presente estudo foi no domínio Relações Sociais, corroborando os resultados de estudos com policiais de diferentes regiões do Brasil, que também encontraram maior escore médio para esse domínio ${ }^{(4,16,18)}$, cujos resultados apontam fortalecimento das relações pessoais, suporte social e prática sexual dos profissionais.

O maior escore obtido pelos policiais da atual pesquisa na faceta Autoestima reforça a relevância social do trabalho para a vida do profissional, relacionada ao orgulho de fazer parte da Polícia Militar ${ }^{(19)}$. Entretanto eventos intrínsecos da atividade policial tornam o processo de trabalho imprevisível. Nesses casos, se os policiais não contarem com estratégias que os ajudem a lidar com os eventos estressores decorrentes da atividade laboral, ficarão sujeitos à exaustão e, consequentemente, ao adoecimento ${ }^{(20,21)}$.

O baixo escore da faceta Ambiente Físico mostra que os policiais da presente investigação merecem atenção em relação às condições estruturais do ambiente de trabalho. Esse resultado reforça a tendência de insatisfação dos policiais em relação ao bem-estar no ambiente de trabalho ${ }^{(19)}$. Para os profissionais, as más condições materiais de trabalho, o espaço físico inadequado, a infraestrutura insuficiente, a falta de contingente humano e a consequente sobrecarga de trabalho comprometem o ambiente sócio-ocupacional e a saúde, gerando desgaste físico, sofrimento mental e adoecimento( ${ }^{(16)}$.

O cansaço físico e a falta de equilíbrio emocional podem levar os policiais a adotarem atitudes irracionais durante crises e situações caóticas, as quais podem ocasionar a falta de eficácia no desempenho do exercício profissional, expondo a população e os próprios policiais a perigos em potencial(6). Nesse contexto, a saúde física dos policiais militares está inclusa nos temas prioritários elencados pela Política Nacional de Promoção da Saúde, exigindo o estímulo a práticas corporais e atividades físicas que favoreçam as condições de saúde dessa população(9).

O preparo físico e mental é fundamental para que os policiais entendam as demandas sociais que direcionam as necessidades de segurança pública ${ }^{(5)}$ e representam, atualmente, um grande desafio ao trabalho da polícia.

Além disso, a insatisfação com a remuneração, evidenciada pelo baixo escore da faceta Recursos Financeiros, faz com que os profissionais exerçam, sempre que possível, outras atividades informais, geralmente aos finais de semana ou em dias e horários alternados com o trabalho da corporação, comprometendo a realização de atividades de recreação e lazer, e potencializando o desgaste físico e mental ${ }^{(3,8)}$.

A carência de recursos financeiros, evidenciada no presente estudo, não é inédita e, embora pouco admitida, já foi constatada em outras oportunidades e é apontada como importante dificultador do trabalho policial(22). De acordo com a literatura, policiais costumam desenvolver outras atividades remuneradas, como vigilantes ou seguranças, que requerem esforço físico e trazem mais riscos e prejuízos à atividade policial ${ }^{(3,8,18)}$.

O reduzido escore observado na faceta Sono e Repouso é corroborado por estudos com policiais da radiopatrulha noturna em Palmas, no Tocantins ${ }^{(23)}$, e policiais da cidade de Porto Alegre, Rio Grande do Sul(21). Uma das causas são os horários de trabalho. $O$ trabalho noturno e as escalas extras desregulam a rotina do sono, levando à indisposição, fadiga, perda de apetite, aumento do consumo de tabaco, comprometendo a saúde dos policiais ${ }^{(18)}$. Além disso, o aumento da carga horária de trabalho, em decorrência de outras atividades laborais, leva à redução das horas diárias de sono, causando fadiga e cansaço, e tornando os profissionais estressados e doentes ${ }^{(2)}$.

Outro aspecto que merece atenção é a faceta Recreação e Lazer, que apresentou baixo escore entre os policiais estudados. Atividades de lazer contribuem para a melhoria da qualidade de vida e devem ser estimuladas. Mesmo pequenas alterações na prática de atividade de lazer estão associadas à melhoria da qualidade de vida desses profissionais ${ }^{(22-24)}$.

A tendência à redução das médias obtidas nos escores Físico, Psicológico e Relações Sociais pelas policiais mulheres da presente investigação corrobora os melhores escores médios entre policiais do sexo masculino apontados pela literatura ${ }^{(7,15)}$.

Geralmente, mulheres policiais relacionam o cotidiano de trabalho ao estresse, sofrendo maior influência dele na sua saúde ${ }^{(3,6)}$. Além disso, apontam problemas com a hierarquia, grande demanda de trabalho e preconceito de gênero como fatores de estresse negativo ${ }^{(7)}$.

A tendência ao aumento da qualidade de vida no domínio Físico, com o aumento do tempo de atuação profissional está relacionada à capacidade de resiliência e ao maior preparo para as atividades laborais, à medida 
que o profissional progride na carreira ${ }^{(16,20)}$. Por outro lado, a responsabilidade assumida em cargos superiores, associada à doutrina e imposições previstas em regulamento da Polícia Militar, podem comprometer a qualidade de vida no domínio Relações Sociais ${ }^{(6)}$, conforme observado no presente estudo.

Por fim, o aumento da carga horária de trabalho pode reduzir a qualidade de vida no domínio Físico, comprometendo o desempenho laboral dos policiais e favorecendo o adoecimento ${ }^{(18)}$. Diante disso, o suporte social entre colegas de trabalho e a autonomia profissional são fatores que contribuem para a percepção positiva da saúde e a melhoria da qualidade de vida dos policiais ${ }^{(16)}$.

Os resultados deste estudo fornecem um diagnóstico real e preciso do comprometimento das facetas Recursos Financeiros, Recreação e Lazer, Ambiente Físico, e Sono e Repouso, e contribuem para a discussão e implementação de ações de promoção de saúde e de aprimoramento das condições de trabalho desses profissionais, favorecendo a segurança da sociedade assistida.

Além disso, permitem a reflexão sobre a qualidade de vida e o trabalho dos policiais militares e contribuem com serviços e profissionais de saúde no direcionamento de ações de promoção de saúde, de prevenção do desgaste físico e dos transtornos emocionais dos policiais. Corroboram, portanto, para a discussão de políticas públicas que melhorem as condições laborais desses trabalhadores, promovendo saúde e qualidade de vida, com base na autonomia e singularidade dos sujeitos e nas particularidades dos ambientes laborais, conforme determina a Política Nacional de Promoção da Saúde ${ }^{(9)}$.

O delineamento transversal e a amostra de conveniência representam limitações do estudo, pois não permitem a generalização dos resultados. Assim, é importante o desenvolvimento de estudos longitudinais, capazes de identificar, precisa e temporalmente, ao longo da carreira, os fatores prejudiciais à qualidade de vida de policiais.

\section{CONCLUSÃO}

O estudo mostrou que os policiais militares avaliados consideram a qualidade de vida boa ou muito boa e encontram-se satisfeitos com a saúde. Há, no entanto, comprometimento da qualidade de vida dos profissionais nos fatores relacionados ao domínio Meio Ambiente.

Não houve diferença significativa da qualidade de vida com a variável sexo, no entanto policiais mulheres tiveram menor qualidade de vida nos domínios Físico, Psicológico e Relações Sociais. O maior tempo de atuação profissional obteve a maior qualidade de vida no domínio Físico e menor no Social. A carga horária de trabalho obteve a menor qualidade de vida no domínio Físico.

\section{CONFLITOS DE INTERESSE}

Autores informam que não há conflitos de interesses.

\section{CONTRIBUIÇÕES}

Thiago Roberto Arroyo e Luciano Garcia Lourenção contribuíram com a elaboração e delineamento do estudo; a aquisição, análise e interpretação dos dados; a redação e/ou revisão do manuscrito; Marcio Andrade Borges contribuiu com a análise e interpretação de dados, e a redação e/ou revisão do manuscrito.

Artigo extraído da dissertação de mestrado intitulada "Qualidade de vida de policiais militares do Comando de Policiamento do Interior - $5^{\mathrm{a}}$ região (CPI-5) do estado de São Paulo". Faculdade de Medicina de São José do Rio Preto, Programa de Pós-graduação em Psicologia e Saúde, 2016, 45 páginas.

\section{REFERÊNCIAS}

1. Cardoso MCB. Os centros de referência em saúde do trabalhador e as ações em saúde mental relacionadas ao trabalho [dissertação] [Internet]. Feira de Santana: Universidade Estadual de Feira de Santana; 2015 [acesso em 2018 Out 13]. Disponível em: http://tede2.uefs.br:8080/bitstream/tede/363/2/ DISSERTA\%C3\%87\%C3\%830\%20CARDOSO\%2C\%20MARIANA.pdf

2. Almeida DM, Lopes LFD, Costa VMF, Santos RCT, Corrêa JS. Satisfação no trabalho dos policiais militares do Rio Grande do Sul: um estudo quantitativo. Psicol Cienc Prof. 2016;36(4):801-15. doi: https://dx.doi. org/10.1590/1982-3703000362016 
3. Alexopoulos EC, Palatsidi V, Tigani X, Darviri C. Exploring stress levels, job satisfaction, and quality of life in a sample of police officers in Greece. Saf Health Work. 2014;5(4):210-5. doi: http://dx.doi.org/10.1016/j. shaw.2014.07.004

4. Souza MJ Filho, Noce F, Andrade AGP, Calixto RM, Albuquerque MR, Costa VT. Avaliação da qualidade de vida de policiais militares. R Bras Ci e Mov [Internet]. 2015 [acesso em 2017 Nov 15];23(4):159-69. Disponível em: https://portalrevistas.ucb.br/index.php/RBCM/article/view/5551/4099

5. Oliveira LCN, Quemelo PRV. Qualidade de vida de policiais militares. Arq Ciên Saúde [Internet]. 2014 [acesso em 2017 Nov 15];21(3):72-5. Disponível em: http://repositorio-racs.famerp.br/racs_ol/vol-21-3/v21-3.htm

6. Guimarães LAM, Mayer VM, Bueno HPV, Minari MRT, Martins LF. Síndrome de Burnout e qualidade de vida de policiais militares e civis. Rev Sul-Am Psicol [Internet]. 2014 [acesso em 2017 Nov 15];2(1):98-122. Disponível em: http://www.revista.unisal.br/am/index.php/psico/article/view/32/44

7. Schneider D, Signorelli MC, Pereira PPG. Mulheres da segurança pública do litoral do Paraná, Brasil: intersecções entre gênero, trabalho, violência(s) e saúde. Ciênc Saúde Colet. 2017;22(9):3003-11. doi: https://doi.org/10.1590/1413-81232017229.07892016

8. Ferreira MO, Dutra FCMS. Avaliação dos fatores psicossociais, saúde mental e capacidade para o trabalho em policiais militares de Uberaba/MG. Rev Psicologia: Saúde Mental e Seg Pública [Internet]. 2017 [acesso em 2018 Out 18];3(6):133-51. Disponível em: https://revista.policiamilitar.mg.gov.br/index.php/psicologia/ article/view/98/198

9. Ministério da Saúde (BR), Secretaria de Vigilância em Saúde, Secretaria de Atenção à Saúde. Política Nacional de Promoção da Saúde: revisão da Portaria MS/GM nº 687, de 30 de março de 2006 [Internet]. Brasília, DF; 2014 [acesso em 2018 Out 13]. Disponível em: http://bvsms.saude.gov.br/bvs/publicacoes/ pnps_revisao_portaria_687.pdf

10. Assembléia Legislativa do Estado (SP). Decreto $n^{\circ} 60.175$, de 25 de fevereiro de 2014 [Internet]. 2014 [acesso em 2017 Nov 15]. Disponível em: http://www.al.sp.gov.br/repositorio/legislacao/decreto/2014/ decreto-60175-25.02.2014.html

11. Governo do Estado (SP), Secretaria de Segurança Pública, Polícia Militar. Insígnias [Internet]. 2017 [acesso em 2018 Out 13]. Disponível em: http://www.policiamilitar.sp.gov.br/institucional/insignias

12. Fleck MPA, Louzada S, Xavier M, Chachamovich E, Vieira G, Santos L, et al. Aplicação da versão em português do instrumento abreviado de avaliação da qualidade de vida "WHOQOL-bref". Rev Saúde Pública. 2000;34(2):178-83. doi: http://dx.doi.org/10.1590/S0034-89102000000200012

13. Pereira RJ, Cotta RMM, Franceschini SCC, Ribeiro RCL, Sampaio RF, Priore SE, et al. Contribuição dos domínios físico, social, psicológico e ambiental para a qualidade de vida global de idosos. Rev Psiquiatr RS [Internet]. 2006 [acesso em 2006 Fev 23];28(1):27-38. Disponível em: http://www.scielo.br/pdf/rprs/v28n1/ v28n1a05

14. Pedroso B, Pilatti LA, Gutierrez GL, Picinin CT. Cálculo dos escores e estatística descritiva do WHOQOLbref através do Microsoft Excel. Rev Bras Qual Vida [Internet]. 2010 [acesso em 2019 Fev 23];2(1):31-6. doi: http://dx.doi.org/10.3895/S2175-08582010000100004

15. Brasil VP, Lourenção LG. Qualidade de vida de policiais militares do interior do estado de São Paulo. Arq Ciênc Saúde. 2017;24(1):81-5. doi: https://doi.org/10.17696/2318-3691.24.1.2017.511

16. Pelegrini A, Cardoso TE, Claumann GS, Pinto AA, Felden EPG. Percepção das condições de trabalho e estresse ocupacional em policiais civis e militares de unidades de operações especiais. Cad Bras Ter Ocup [Internet]. 2018 [acesso em 2018 Out 13];26(2):423-30. doi: https://doi.org/10.4322/2526-8910.ctoAO1160

17. Pinto LW, Figueiredo AEB, Souza ER. Sofrimento psíquico em policiais civis do Estado do Rio de Janeiro. Ciênc Saúde Coletiva. 2013;18(3):633-44. doi: http://dx.doi.org/10.1590/S1413-81232013000300009

18. Jesus GM, Jesus EFA. Nível de atividade física e barreiras percebidas para a prática de atividades físicas entre policiais militares. Rev Bras Ciênc Esporte. 2012;34(2):433-48. doi: http://dx.doi.org/10.1590/S010132892012000200013

19. Souza CFC. Avaliação da qualidade de vida no trabalho: um estudo entre policiais militares do $8^{\circ}$ comando 
de policiamento de área de Sorriso - MT. RHM [Internet]. 2012 [acesso em 2017 Nov 15];8(1):26-47. Disponível em: http://revistacientifica.pm.mt.gov.br/ojs/index.php/semanal/article/view/180/pdf_78

20. Kaur R, Chodagiri VK, Reddi NK. A psychological study of stress, personality and coping in police personnel. Indian J Psychol Med. 2013;35(2):141-47. doi: http://dx.doi.org/10.4103/0253-7176.116240

21. Pinto JN, Perin C, Dick NRM, Lazzarotto AR. Avaliação do sono em um grupo de policiais militares de elite. Acta Paul Enferm [Internet]. 2018 [acesso em 2018 Out 13];31(2):153-61. doi: http://dx.doi.org/10.1590/19820194201800023

22. Liz CM, Silva LC, Arab C, Viana MS, Brandt R, Vasconcellos DIC, et al. Características ocupacionais e sociodemográficas relacionadas ao estresse percebido de policiais militares. Rev Cub Med Mil [Internet]. 2014 [acesso em 2017 Nov 15];43(4):467-80. Disponível em: http://scielo.sld.cu/scielo.php?script=sci_arttext \&pid=S0138-65572014000400007

23. Alcanfor LM, Costa VA. Qualidade de vida no trabalho policial: as estratégias organizacionais para minimizar os impactos da privação de sono à saúde do policial militar que desempenha a radiopatrulha noturna. REBESP [Internet]. 2016 [acesso em 2017 Nov 15];9(1):1-19. Disponível em: http://revista.ssp.go.gov.br/ index.php?journal=rebesp\&page $=$ article\&op $=$ view\&path $\% 5 \mathrm{~B} \% 5 \mathrm{D}=224$

24. Dorileo AW, Souza CFC. Qualidade de vida no trabalho: um estudo entre policiais militares do $12^{\circ}$ Batalhão de Polícia Militar. RHM [Internet]. 2017 [acesso em 2017 Nov 15];17(3):161-90. Disponível em: http:// revistacientifica.pm.mt.gov.br/ojs/index.php/semanal/article/view/381/pdf

\section{Endereço do primeiro autor:}

Thiago Roberto Arroyo

Faculdade de Medicina de São José do Rio Preto - FAMERP

Av. Brigadeiro Faria Lima, 5416

Bairro: Vila São Pedro

CEP: 15090-000 - São José do Rio Preto - SP - Brasil

E-mail: trarroyo@yahoo.com.br

\section{Endereço para correspondência:}

Luciano Garcia Lourenção

Universidade Federal do Rio Grande - FURG

Campus da Saúde

Rua General Osório, s/n

Bairro: Centro

CEP: 96201-900 - Rio Grande - RS - Brasil

E-mail: luciano.famerp@gmail.com

Como citar: Arroyo TR, Borges MA, Lourenção LG. Saúde e qualidade de vida de policiais militares. Rev Bras Promoç Saúde. 2019;32:7738. 